\title{
Selection of Bacillus species for targeted in situ release of prebiotic galacto- rhamnogalacturonan from potato pulp in piglets
}

Jers, Carsten; Strube, Mikael Lenz; Cantor, Mette D; Nielsen, Bea K K; Sørensen, Ole Brøsted; Boye, Mette; Meyer, Anne S.

Published in:

Applied Microbiology and Biotechnology

Link to article, DOI:

$10.1007 / \mathrm{s} 00253-017-8176-x$

Publication date:

2017

Document Version

Peer reviewed version

Link back to DTU Orbit

Citation (APA):

Jers, C., Strube, M. L., Cantor, M. D., Nielsen, B. K. K., Sørensen, O. B., Boye, M., \& Meyer, A. S. (2017). Selection of Bacillus species for targeted in situ release of prebiotic galacto-rhamnogalacturonan from potato pulp in piglets. Applied Microbiology and Biotechnology, 101(9), 3605-3615. https://doi.org/10.1007/s00253-017$8176-x$

\section{General rights}

Copyright and moral rights for the publications made accessible in the public portal are retained by the authors and/or other copyright owners and it is a condition of accessing publications that users recognise and abide by the legal requirements associated with these rights.

- Users may download and print one copy of any publication from the public portal for the purpose of private study or research.

- You may not further distribute the material or use it for any profit-making activity or commercial gain

- You may freely distribute the URL identifying the publication in the public portal 
Selection of Bacillus species for targeted in situ release of prebiotic galactorhamnogalacturonan from potato pulp in piglets

Carsten Jers ${ }^{\mathrm{a},}$, , Mikael L. Strube ${ }^{\mathrm{a}}$, Mette D. Cantor ${ }^{\mathrm{b}}$, Bea K. K. Nielsen ${ }^{\mathrm{b}}$, Ole B. Sørensen ${ }^{\mathrm{c}}$, Mette Boye $^{\mathrm{d}, \mathrm{e}}$, Anne S. Meyer ${ }^{\mathrm{a}}$

${ }^{a}$ Department of Chemical and Biochemical Engineering, Technical University of Denmark, 2800 Kgs. Lyngby, Denmark

${ }^{\mathrm{b}}$ Chr. Hansen A/S, Bøge Alle 10-12, 2970 Hørsholm, Denmark

${ }^{c}$ KMC amba, Herningvej 60, 7330 Brande, Denmark

${ }^{\mathrm{d}}$ National Veterinary Institute, Technical University of Denmark, 1870 Frederiksberg, Denmark.

${ }^{\mathrm{e}}$ Present address: Department of Veterinary and Animal Sciences, Faculty of Health and Medical Sciences, University of Copenhagen, Frederiksberg, Denmark

\section{To whom correspondence should be addressed:}

Carsten Jers, e-mail: cjer@dtu.dk

Keywords: Bacillus, probiotic, prebiotic, rhamnogalacturonan, piglet, B. mojavensis

\section{Acknowledgements}

We would like to express our gratitude to Annette Eva Jensen for expert technical assistance pertaining to the HPSEC analyses. APHA Scientific (United Kingdom) is acknowledged for the provision of a strain (B. mojavensis 10894) used in this study. This work was supported by a grant from the Green Development and Demonstration Programme (GUDP), Ministry of Environment and Food of Denmark (Grant no 34009-13-0700). 


\begin{abstract}
We have previously shown that galacto-rhamnogalacturonan fibers can be enzymatically extracted from potato pulp and that these fibers have potential for exerting a prebiotic effect in piglets. The spore-forming Bacillus species are widely used as probiotics in feed supplements for pigs. In this study we evaluated the option for further functionalising Bacillus feed supplements by selecting strains possessing the enzymes required for extraction of the potentially prebiotic fibers. We established that it would require production and secretion of pectin lyase and/or polygalacturonase but no or limited secretion of galactanase and $\beta$-galactosidase. By screening a library of 158 Bacillus species isolated from feces and soil, we demonstrated that especially strains of Bacillus amyloliquefaciens, Bacillus subtilis and Bacillus mojavensis have the necessary enzyme profile and thus the capability to degrade polygalacturonan. Using an in vitro porcine gastrointestinal model system, we revealed that specifically strains of $B$. mojavensis were able to efficiently release galacto-rhamnogalacturonan from potato pulp under simulated gastrointestinal conditions. The work thus demonstrated the feasibility of producing prebiotic fibers via a feed containing Bacillus spores and potato pulp and identified candidates for future in vivo evaluation in piglets.
\end{abstract}

\title{
Introduction
}

There is an increasing need for development and application of pre- and probiotic feed supplements as an alternative to the use of antibiotics and zinc in the pig production industry. In this respect, the spore-forming, Gram-positive Bacillus species are of particular interest. Although historically considered strictly aerobic bacteria, Bacillus species are facultative anaerobes that can grow by fermentation or by using nitrate or nitrite as electron acceptor (Nakano et al. 1997). Bacillus spores are also readily found in feces and experimental data supports that spore germination, outgrowth and re-sporulation occurs in the gastrointestinal (GI) tract (Tam et al. 2006). Several Bacillus species, mainly Bacillus subtilis, Bacillus clausii, Bacillus cereus, Bacillus coagulans, and Bacillus licheniformis, are already being used as probiotic supplements for animals and humans (Cutting 2011; Larsen et al. 2014; Majeed et al. 2016). The main advantages of Bacillus species over e.g. Bifidobacterium and Lactobacillus are the ability to form spores that can survive the low $\mathrm{pH}$ experienced in the stomach and the possibility of long-term storage of spores with no adverse effect on viability (Cutting 2011). 
The use of spore preparations of specific Bacillus strains as probiotics have been successfully evaluated in pigs. A field study demonstrated that Bacillus probiotics can improve weight gain and feed conversion while reducing disease in pigs (Alexopoulus et al. 2004). B. subtilis probiotics were also shown to reduce the effects of experimental infection with Shiga toxinproducing and enterotoxigenic Escherichia coli (Tsukahara et al. 2013; Bhandari et al. 2008). The latter study indicated that this effect was by competition for attachment sites in the GI tract rather than a direct effect on E. coli (Bhandari et al. 2008). Bacillus probiotics have also been shown to elicit an altered immunological response (Altmeyer et al. 2014; Scharek-Tedin et al. 2013). Although probiotic effects have been attributed to Bacillus species, the modes of action, and even whether the effects are due to vegetative cells or spores, are largely unknown. In case of the pathogen Bacillus anthracis it is known that the spore itself can elicit an immunological response (Kang et al. 2008), whereas other immunological effects of Bacillus species are attributed to vegetative cells and secreted effectors (Huang et al. 2008; Okamoto et al. 2012). In pigs, spores of B. subtilis and B. licheniformis can germinate in the GI tract of pigs, but only limited growth of vegetative cells has been observed (Leser et al. 2008). This could indicate that the reported probiotic effects are in fact not mediated by a high number of growing cells.

With improved understanding of the molecular mechanisms of probiotic action, it seems plausible that blends of probiotic strains can be designed for targeting a wider array of probiotic functions as well as improving the feed utilization. In case of the latter, it has previously been noted that some Bacillus species secrete a wide array of enzymes that among other things aid in the decomposition of complex feed molecules (Latorre et al. 2014). We have previously shown that potato pulp, a side product from industrial potato starch production, can be enzymatically treated to release prebiotic fibers. Potato pulp is rich in pectin and in particular the galactanbranched rhamnogalacturonan type I pectin (Thomassen et al. 2011). Pectin lyase and polygalacturonase are two enzymes that act on the pectin backbone. Polygalacturonase hydrolyses the $\alpha-1,4$-bonds galacturonic acid residues in the pectin backbone whereas pectin lyase can cleave the pectin backbone by $\beta$-elimination (Kashyap et al. 2001; Yadav et al. 2009). By the action of pectin lyase and/or polygalacturonase, high-molecular weight $(>100 \mathrm{kDa})$ fibers consisting of primarily galacto-rhamnogalacturonan are released both in vitro (Thomassen et al. 2011, Strube et al. 2015a) and in vivo in piglets (Strube et al. 2015b). When tested in vitro in human fecal samples, these extracted potato fibers stimulated the growth of species of both Bifidobacterium and Lactobacillus (Thomassen et al. 2011). A positive effect on growth of indigenous Lactobacillus was 
also observed in a recent in vitro fermentation study using terminal ileum content from piglets (Strube et al. 2015a).

We previously demonstrated that galacto-rhamnogalacturonan can be released enzymatically from potato pulp by pectin lyase and polygalacturonase in the GI tract of piglets (Strube et al. 2015b). Bacillus spore probiotics are already used in pigs and these bacteria would have a potential to produce pectin lyase and polygalacturonase in situ in the GI tract. The aim of this study was thus to identify potential probiotic strains capable of producing the enzymes necessary for release of prebiotic fibers (pectin lyase and/or polygalacturonase) from potato pulp with minimal production of fiber-degrading enzymes (galactanase and $\beta$-galactosidase). Starting from a diverse collection of spore-forming Bacillus species we demonstrate that especially strains of B. amyloliquefaciens, B. subtilis and Bacillus mojavensis have the desired enzyme profile and when tested in an in vitro GI tract model two strains of B. mojavensis were able to efficiently release the desired, potentially prebiotic fibers from potato pulp.

\section{Materials and methods}

\section{Bacterial strains and growth conditions}

A collection of 158 bacterial fecal and soil isolates of the genus Bacillus were analysed in this study. The strains were isolated from mainly feces of humans, chickens and pigs or from soil (Supplementary Table S1). Strain 10894 that is identical to isolate 37 in (Barbosa et al. 2005) was obtained from APHA scientific (Addlestone, Surrey United Kingdom). The strains were maintained in LB medium (10 g/L tryptone, $5 \mathrm{~g} / \mathrm{L}$ yeast extract, and $10 \mathrm{~g} / \mathrm{L} \mathrm{NaCl})$ with $20 \%$ glycerol frozen at $-80{ }^{\circ} \mathrm{C}$. The strains were cultured shaking at $39{ }^{\circ} \mathrm{C}$ (this temperature was selected to mimic the temperature in piglets) in LB medium with or without $5 \mathrm{~g} / \mathrm{L}$ apple pectin and in pectin minimal medium $\left(1.37 \mathrm{~g} / \mathrm{L}\right.$ trisodium citrate $\cdot 2 \mathrm{H}_{2} \mathrm{O}, 6.0 \mathrm{~g} / \mathrm{L} \mathrm{KH}_{2} \mathrm{PO}_{4}, 14 \mathrm{~g} / \mathrm{L} \mathrm{K} \mathrm{K}_{2} \mathrm{HPO}_{4}, 2.0 \mathrm{~g} / \mathrm{L}$ ammonium sulfate, $0.39 \mathrm{~g} / \mathrm{L} \mathrm{MgSO}_{4} \cdot 7 \mathrm{H}_{2} \mathrm{O}, 73 \mu \mathrm{g} / \mathrm{L} \mathrm{CaCl}_{2} \cdot 2 \mathrm{H}_{2} \mathrm{O}, 212 \mu \mathrm{g} / \mathrm{L} \mathrm{FeCl}_{2} \cdot 4 \mathrm{H}_{2} \mathrm{O}, 10 \mu \mathrm{g} / \mathrm{L} \mathrm{MnCl}_{2}$. $4 \mathrm{H}_{2} \mathrm{O}, 17 \mu \mathrm{g} / \mathrm{L} \mathrm{ZnCl}, 4.3 \mu \mathrm{g} / \mathrm{L} \mathrm{CuCl}_{2} \cdot 2 \mathrm{H}_{2} \mathrm{O}, 3.3 \mu \mathrm{g} / \mathrm{L} \mathrm{CoCl}_{2}, 6.0 \mu \mathrm{g} / \mathrm{L} \mathrm{Na}_{2} \mathrm{MoO}_{4} \cdot 2 \mathrm{H}_{2} \mathrm{O}$, and 4.3 $\mu \mathrm{g} / \mathrm{L} \mathrm{Na}_{2} \mathrm{SeO}_{3}$ with $5.0 \mathrm{~g} / \mathrm{L}$ apple pectin) (Ochiai et al. 2007). For production of spores, the strains were cultured in sporulation medium ( $8 \mathrm{~g} / \mathrm{L}$ Difco Nutrient broth (BD, New Jersey, USA), 1/g L $\mathrm{KCl}, 0.25 \mathrm{~g} / \mathrm{L} \mathrm{MgSO}_{4} \cdot 7 \mathrm{H}_{2} \mathrm{O}, 2.0 \mathrm{mg} / \mathrm{L} \mathrm{MnCl}_{2} \cdot 4 \mathrm{H}_{2} \mathrm{O}, 55.5 \mathrm{mg} / \mathrm{L} \mathrm{CaCl}_{2}$, and $1.52 \mu \mathrm{g} / \mathrm{L} \mathrm{FeSO}_{4}(\mathrm{pH}$ 
7.0) (Schaeffer et al. 1965). For evaluation of biofilm formation, the strains were grown in biofilm medium (LB medium supplemented with $0.1 \mathrm{mM} \mathrm{MnCl}_{2}$, and $3 \% \mathrm{v} / \mathrm{v}$ glycerol) (Trejo et al. 2013).

\section{Preparation of secreted enzymes}

To produce secreted enzymes for the primary screening, the 158 strains were grown in microtiter plates. A $150 \mu \mathrm{L}$ pre-culture in LB was grown shaking (250 rpm, $5 \mathrm{~mm}$ amplitude) in a low well, round bottom Nunc microtiter plate (ThermoFisher, Massachusetts, USA) covered with an Airpore sheet (Qiagen, Hilden, Germany) for $8 \mathrm{~h}$. Subsequently, $40 \mu \mathrm{L}$ of this culture was used to inoculate $1 \mathrm{~mL} \mathrm{LB}$ pectin or pectin minimal medium in a $2 \mathrm{~mL}$ deep well microtiter plate (Eppendorf, Hamburg, Germany) and the cells were cultured an additional $16 \mathrm{~h}$. Some strains produced surface biofilms. This was detached by mixing at $1400 \mathrm{rpm}$ for $10 \mathrm{~s}$ followed by centrifugation at $5000 \mathrm{~g}$ for 15 min at $4{ }^{\circ} \mathrm{C}$ to pellet cells. To the supernatant, containing the secreted enzymes, glycerol was added to a final concentration of $10 \%$ before storage at $-20{ }^{\circ} \mathrm{C}$ until further analyses. The secreted enzymes were subsequently assayed for pectin lyase, polygalacturonase, galactanase, and $\beta$ galactosidase activity as described below.

In order to assay release of galacto-rhamnogalacturonan from potato pulp, enzyme supernatants were made from select strains by inoculating a colony in $4 \mathrm{~mL} \mathrm{LB}$ and incubating with shaking at $39{ }^{\circ} \mathrm{C}$ for $8 \mathrm{~h}$. The pre-culture was subsequently diluted 100 -fold in $50 \mathrm{~mL}$ LB with pectin or pectin minimal medium in a $250 \mathrm{~mL}$ shake flask and grown with shaking at $39{ }^{\circ} \mathrm{C}$ for 16 $\mathrm{h}$. The cells were removed by three rounds of centrifugation at $5000 \mathrm{~g}$ and glycerol was added to 10 $\%$ final concentration. Enzyme solutions were stored at $-20{ }^{\circ} \mathrm{C}$ until further analyses.

\section{Pectin lyase activity assay}

Pectin lyase activity was measured in a reaction containing $50 \mathrm{mM}$ phosphate-citrate buffer (pH 7), and $1.0 \mathrm{mg} / \mathrm{L}$ apple pectin (Sigma, Steinheim, Germany) at $39{ }^{\circ} \mathrm{C}$. The reactions were initiated by the addition of enzyme and were then followed spectrophotometrically at $235 \mathrm{~nm}$ (Yadav et al. 2009). In a $100 \mu \mathrm{L}$ reaction, $5 \mu \mathrm{L}$ enzyme supernatant was used. Reaction rates were calculated based on the initial linear part of the reaction. One unit of enzyme activity was defined as the amount of enzyme catalyzing the release of $1 \mu \mathrm{mol}$ of unsaturated uronide per minute. The extinction coefficient used was $5.5 \mathrm{mM}^{-1} \mathrm{~cm}^{-1}$ (van den Broek et al. 1997). Reactions were done in duplicates. 


\section{Polygalacturonase activity assay}

Polygalacturonase activity was measured semi-quantitatively using a modified assay based on precipitation of polygalacturonic acid with the dye ruthenium red (Torres et al. 2011). The polygalacturonase activity was measured in $50 \mathrm{mM}$ phosphate-citrate $(\mathrm{pH} \mathrm{7})$ and $1.87 \mathrm{mg} / \mathrm{mL}$ polygalacturonic acid (Sigma, Steinheim, Germany) at $39{ }^{\circ} \mathrm{C}$. The reaction was stopped by diluting the sample 31.6-fold in $100 \mathrm{mg} / \mathrm{L}$ ruthenium red, mixing at $1400 \mathrm{rpm}$ and centrifugation at $5000 \mathrm{~g}$ for $10 \mathrm{~min} .250 \mu \mathrm{L}$ supernatant was transferred to a microtiter plate and absorbance at $535 \mathrm{~nm}$ was recorded. $10 \mu \mathrm{L}$ enzyme supernatant was used in a $40 \mu \mathrm{L}$ reaction, and the reaction was incubated for $20 \mathrm{~h}$. One unit of polygalacturonase activity in this assay is defined as the amount of enzyme catalyzing the hydrolysis of $1 \mu \mathrm{g}$ of polygalacturonic acid to smaller fragments unable to precipitate with the dye per minute under the assay conditions (Torres et al. 2011). Reactions were done in duplicates.

\section{Galactanase activity assay}

Galactanase activity was measured in a reaction containing $50 \mathrm{mM}$ phosphate-citrate buffer (pH 7), and $10 \mathrm{~g} / \mathrm{L}$ azo-galactan (Megazyme, Wicklow, Ireland) at $39{ }^{\circ} \mathrm{C}$ according to manufacturer's instruction. Reactions were stopped by transferring $100 \mu \mathrm{L}$ sample to $250 \mu \mathrm{L}$ of $96 \%$ ethanol, mixing at $1400 \mathrm{rpm}$ and centrifugation at $4400 \mathrm{~g}$ for $5 \mathrm{~min}$ at $4{ }^{\circ} \mathrm{C}$. $200 \mu \mathrm{L}$ supernatant was transferred to a microtiter plate and absorbance at $590 \mathrm{~nm}$ was recorded. In the initial screen, $25 \mu \mathrm{L}$ enzyme supernatant was used in a $100 \mu \mathrm{L}$ reaction, and reactions were sampled after 1,2 , and $4 \mathrm{~h}$ and reaction rates were calculated. Reactions were done in duplicates.

\section{$\beta$-galactosidase activity assay}

Measurement of secreted $\beta$-galactosidase activity was done in an assay modified from (Jers et al. 2011). Briefly, the activity was measured in an assay with $4 \mathrm{~g} / \mathrm{L} o$-nitrophenyl- $\beta$-galactoside in Zbuffer $\left(60 \mathrm{mM} \mathrm{Na}_{2} \mathrm{HPO}_{4}, 40 \mathrm{mM} \mathrm{NaH} \mathrm{PO}_{4}, 10 \mathrm{mM} \mathrm{KCl}\right.$, and $1.0 \mathrm{mM} \mathrm{MgSO}$, pH 7.0). The reactions were initiated by addition of enzyme and incubated at $39{ }^{\circ} \mathrm{C}$. Reactions were terminated by adding $100 \mu \mathrm{L}$ of $0.5 \mathrm{M} \mathrm{Na}_{2} \mathrm{CO}_{3}$ to $100 \mu \mathrm{L}$ sample and absorbance at $420 \mathrm{~nm}$ was recorded. Reactions were sampled after 1, 2, and $4 \mathrm{~h}$ and reaction rates were calculated. Reactions were done in duplicates. 


\section{Enzymatic release of galacto-rhamnogalacturonan from potato pulp}

Enzyme reactions contained 0.4 g potato pulp (FiberBind400; KMC, Denmark) in $20 \mathrm{~mL}$. For testing Bacillus supernatant samples, $2 \mathrm{~mL}$ supernatant was used. The reaction mix was incubated in a $50 \mathrm{~mL}$ centrifuge tube on a rocking mixer at $39{ }^{\circ} \mathrm{C}$ and samples were stopped at indicated times. Subsequently the mix was centrifuged at $5000 \mathrm{~g}$ for $10 \mathrm{~min}$ and the supernatant was filtered through a filter paper (VWR, 5-13 $\mu \mathrm{m}$ retention). Extracted galacto-rhamnogalacturonan in the filtrate was precipitated by addition of isopropanol to a final concentration of $70 \%(\mathrm{v} / \mathrm{v})$, centrifuged for $15 \mathrm{~min}$ at $5000 \mathrm{~g}$ and pellets were dried in a vacuum lyophiliser and weighed. Dried samples were analysed by size exclusion as described below. Reactions were done in duplicates.

\section{Species determination}

Species determination of all isolates was done based on 16S rRNA gene sequences and for select strains, this was complemented with analysis of $g y r B$ and $r p o B$ genes as described previously (Larsen et al. 2014).

\section{Spore preparation}

A colony was inoculated in $3 \mathrm{~mL} \mathrm{LB}$ medium and cultured with shaking for $6 \mathrm{~h}$ at $37^{\circ} \mathrm{C} .50 \mathrm{~mL}$ sporulation medium in a $250 \mathrm{~mL}$ flask was inoculated with $1 \mathrm{~mL}$ pre-culture and cultured with shaking at $37{ }^{\circ} \mathrm{C}$ for $24 \mathrm{~h}$. The spores were harvested by centrifugation at $5000 \mathrm{~g}$ for $15 \mathrm{~min}$ at $4{ }^{\circ} \mathrm{C}$, washed three times with $20 \mathrm{~mL}$ sterile water and subsequently resuspended in $4 \mathrm{~mL}$ sterile water. Prior to harvest the degree of sporulation was evaluated by microscopy, and the concentration was estimated by plating serial dilutions on LB agar plates and counting colony forming units (Schaeffer et al. 1965).

\section{Pellicle formation assay}

To make a pre-culture, a colony was inoculated in $3 \mathrm{~mL} \mathrm{LB}$ medium and cultured with shaking for $6 \mathrm{~h}$ at $37^{\circ} \mathrm{C}$. In a 6 -well microtiter plate, $10 \mathrm{~mL}$ of biofilm medium was inoculated with $10 \mu \mathrm{L}$ preculture, and the plate was kept without shaking at $39{ }^{\circ} \mathrm{C}$ for $17 \mathrm{~h}$. At this point, the pellicles were photographed. The experiment was done in duplicates.

\section{In vitro porcine GI model}


Simulation of the conditions in the GI tract was done as reported before (Strube et al. 2015a) with modifications. To simulate stomach conditions, we used $0.25 \mathrm{~g}$ sterilised potato pulp, $0.25 \mathrm{~g}$ pig feed (Svinefoder 5, NAG, Helsinge, Denmark), and $0.32 \mathrm{mg} / \mathrm{mL}$ pepsin (P7125; Sigma, Steinheim, Germany) in $12.5 \mathrm{~mL}$ water and adjusted $\mathrm{pH}$ to $\sim 3$ using $160 \mu \mathrm{L} 1 \mathrm{M} \mathrm{HCl}$. Spores were added to a final concentration of $1 \cdot 10^{7}$ spores $/ \mathrm{mL}$ and incubated at $39^{\circ} \mathrm{C}$, with shaking at $110 \mathrm{rpm}$. After $1 \mathrm{~h}$, to simulate the small intestine, $5 \mathrm{~mL} 1 \%$ porcine bile salts (B8631; Sigma, Steinheim, Germany) and $7.5 \mathrm{~mL}$ of $5.33 \mathrm{mg} / \mathrm{mL}$ porcine pancreatin (8049-47-6; Sigma, Steinheim, Germany) in $40 \mathrm{mM}$ $\mathrm{NaHCO}_{3}$ were added and incubation was continued for 8, 16, 20 or $24 \mathrm{~h}$. Separate reactions were made for each data point. Potato pulp and pig feed were sterilized by autoclaving the dry material at $121{ }^{\circ} \mathrm{C}$ for $10 \mathrm{~min}$ and the stocks of pepsin, bile salts, and pancreatin were filter-sterilized. Released rhamnogalacturonan was precipitated in $70 \%(\mathrm{v} / \mathrm{v})$ isopropanol as described above and dried samples were weighed and analysed by high performance size exclusion chromatography (HPSEC) as described below.

\section{High performance size exclusion chromatography (HPSEC)}

HPSEC was performed on a system consisting of a P680 HPLC pump, an ASI-100 automated sample injector, and an RI-101 refractive index detector (Dionex Corp., Sunnyvale, CA). 100 mM sodium acetate $(\mathrm{pH}$ 6) with $0.02 \%$ sodium azide was used as mobile phase and sample solution matrix and samples were separated on a Shodex SB-806 HQ GPC column 300x8mm) with a Shodex SB-Gguard column (50x6 mm) from Showa Denko K.K. (Tokyo, Japan) as described previously (Rasmussen and Meyer 2010). The precipitated material was dissolved to $5 \mathrm{mg} / \mathrm{mL}$ by vigorous shaking for $6 \mathrm{~h}$ at $60{ }^{\circ} \mathrm{C}$, centrifuged (8000 g, $4 \mathrm{~min}$ ) and filtered using a $0.22 \mu \mathrm{m}$ syringe filter. Pullulan of sizes 800, 400, 110, 12, and $1.3 \mathrm{kDa}$ was used as molecular standards. To provide a quantitative measure for comparison of the strains, the amount of released fibers with a molecular weight higher than $110 \mathrm{kDa}$ was estimated by determining the area under the curve in the HPSEC chromatograms from time points $15 \mathrm{~min}$ to $20 \mathrm{~min}$. This value was adjusted with respect to the dry weight of precipitate obtained.

\section{Monosaccharide composition analysis}

Monosaccharide composition of purified fibres was analysed with a modified and scaled down NREL sulphuric acid hydrolysis (Strube et al. 2015b). In short, samples were hydrolysed by sulphuric acid, followed by quantification on a high-pH anion-exchange chromatography 
(HPAEC)-pulsed amperometric detection (PAD) system using a Dionex CarboPac PA1 analytical column ( $2 \mathrm{~mm}$ by $250 \mathrm{~mm}$ ) combined with a CarboPac PA1 precolumn $(2 \mathrm{~mm}$ by $50 \mathrm{~mm})$ and 0.25 to $500 \mathrm{mM} \mathrm{NaOH}$. Standards of fucose, rhamnose, arabinose, galactose, glucose, xylose, galacturonic acid, and glucuronic acid were included.

\section{Strain deposition}

Among the Bacillus isolates selected for further analyses, representative strains have been deposited in the DSMZ collection (Deutsche Sammlung von Mikroorganismen and Zellkulturen GmbH, Germany). This includes B. subtilis strain 15179 (DSM 25841), B. amyloliquefaciens strain 15111 (DSM 27032), and B. mojavensis strain 15079 (DSM 32357).

\section{Statistics}

Means and standard deviations were calculated using Excel (Microsoft, Washington, USA). Oneway analysis of variance and Tukey's posthoc honest significant difference (HSD) test was performed using R version 2.12.1 (R Core Team, 2012).

\section{Results}

\section{Selection of Bacillus sp. strains with pectinolytic enzymes}

For the purpose of releasing high molecular weight, galactan-rich rhamnogalacturonan from potato pulp we considered it necessary that the strains should possess either pectin lyase or polygalacturonase activity (Thomassen et al. 2011). In addition to prevent further degradation of the extracted polysaccharides, it was desirable if the galactanase and $\beta$-galactosidase activity was minimal. To evaluate the potential of a library consisting of 158 bacterial strains, we performed a primary screen testing for these four enzyme activities. Here the bacteria were grown aerobically in both a rich and a minimal medium. Pectin was added to both growth media, because it has been shown previously to induce expression of genes involved in pectin degradation (Ochiai et al. 2007). The growth medium was subsequently assayed for the secreted enzymes of relevance, and this led to the identification of 20 Bacillus strains that met the outlined criteria (Table 1, Supplementary Table S1). Of the 20 strains, 12 belonged to the species B. amyloliquefaciens that in particular appeared to have the desired enzyme profile. While the pectin lyase and/or polygalacturonase 
activity was moderate, the activity of galactanase and $\beta$-galactosidase was very low or below detection limit. More heterogeneity was observed for the group of B. subtilis/mojavensis where several strains contained all four enzyme activities (Supplementary Table S1). From this group, eight strains were selected that in general had high pectin lyase and/or polygalacturonase activity and low or moderate galactanase and $\beta$-galactosidase activity.

B. licheniformis strains in general primarily expressed galactanase and $\beta$-galactosidase activity. The Bacillus pumilis/safensis group primarily produced galactanase although some strains in addition produced polygalacturonase. The groups of Bacillus aryabhatti/megaterium and Bacillus simplex did not have significant levels of any of the four enzyme activities (Supplementary Table $\mathrm{S} 1$ ). Of the 158 strains, four strains did not grow in either of the media used (however several more grew poorly in the media).

\section{Enzymes from Bacillus sp. can release galacto-rhamnogalacturonan from potato pulp}

Having identified strains with the desired enzyme profile, we wanted to assess whether enzyme extracts from the 20 strains would allow release of galacto-rhamnogalacturonan from the target substrate potato pulp. To examine this, the strains were grown in shake flasks and the supernatant fractions containing secreted enzymes were added to potato pulp. This demonstrated that all strains, to various degrees, were capable of releasing high molecular weight, water-soluble fibers from potato pulp (Supplementary Fig. S1). The supernatants of strains of B. subtilis (10891) and B. mojavensis (10894) were the most proficient in releasing rhamnogalacturonan (Fig. 1). To support that the release was attributed to the enzymes screened for, we also tested the enzyme extract of $B$. subtilis strain 9927 that was found to have insignificant pectin lyase and polygalacturonase activity in the primary screen of enzyme activity, and this strain was not capable of releasing fibers from potato pulp (Fig. 1). Strains of B. amyloliquefaciens in general released a limited amount of fibers, and consequently the moderate pectin lyase and polygalacturonase activity in these strains appeared to be insufficient to completely catalyse release of the fibers from potato pulp within the time frame of the experiment. In conclusion, we demonstrated that the selected strains, when grown aerobically in a standard laboratory growth medium in shake flasks, can produce the enzymes needed for release of rhamnogalacturonan from potato pulp.

\section{Sporulation and biofilm formation}


Next we wanted to establish whether the selected strains would also be capable of releasing the fibers when grown in a simulated porcine GI environment. In the suggested application of the strains, the piglets would be fed with a feed supplement of a Bacillus spore preparation and potato pulp. It is consequently of importance for the industrial application that the strains can efficiently sporulate. In this study, spores were prepared using a standard procedure for B. subtilis (Schaeffer et al. 1965). Using this method, spore concentration was in the order $10^{8}$ spores $/ \mathrm{mL}$. The degree of sporulation was assessed by microscopy, and while most strains exhibited an efficient sporulation (>90 \% spores), B. subtilis strains 5036 and 4208 only yielded about 50-60\% spores. This was not improved substantially by prolonged incubation (up to 3 days).

It has previously been suggested that biofilm formation of Bacilli is a prerequisite for prolonged persistence in the intestine (Tam et al. 2006; Prieto et al. 2014) and we therefore tested for the ability to produce biofilm specifically testing for pellicle formation in order to include the biofilm formation ability in our assessment of the suitability of the strains. Using this approach, all selected strains with the exception of B. subtilis strain 5036 were able to produce robust biofilms (Supplementary Fig. S2). Bile tolerance is another important parameter when evaluating the probiotic potential of the strains. In that respect, the strains were tested for bile tolerance in a previous study, and shown to be able to grow in the presence of $0.3 \%$ bile salts (Larsen et al. 2014).

\section{B. mojavensis can catalyse release of galacto-rhamnogalacturonan from potato pulp under simulated porcine GI conditions}

Finally, we wanted to test whether the bacterial strains under simulated porcine GI conditions would also be able to release galacto-rhamnogalacturonan from potato pulp. To this end, we modified an in vitro GI model previously employed for analysing the performance of purified enzymes (Strube et al. 2015a). The main differences were the inclusion of pig feed in the model system and prolonged incubation times to allow for outgrowth of spores and production of the enzymes. In this more relevant model system, a larger discrimination of performance was observed (Fig. 2; Supplementary Fig. S3). The most proficient strains were the two B. mojavensis strains 10894 and 15079. Only in the case of B. mojavensis 10894, we were able to detect release of fibers from potato pulp after $8 \mathrm{~h}$. For this strain, the amount of released, high-molecular weight fibers was maximal between 16 and $20 \mathrm{~h}$ after which the fibers were subsequently degraded. The profile was similar for B. mojavensis 15079 but the fiber release was delayed perhaps due to small differences in either inoculum or tolerance to the growth conditions. As we here used a more complex medium, 
it was relevant to assure that it was in fact the desired galacto-rhamnogalacturonan fibres that were released. We therefore analysed the composition of the fibres from reactions with $B$. mojavensis strains 10894 and 15079 (Table 2) and found the composition to be similar to that of enzymatically extracted fiber (Strube et al. 2015a) confirming the integrity of the released fiber. The remaining strains of B. amyloliquefaciens and B. subtilis released no or only very small amounts of fibers under these conditions. In general, the B. amyloliquefaciens strains were able to release more galacto-rhamnogalacturonan from potato pulp than strains belonging to B. subtilis.

\section{Discussion}

Species belonging to the genus Bacillus generally have a genome twice the size of members of the genus Lactobacillus and thus a higher genome capacity for encoding enzymes for degradation of various food sources (Fogel et al. 1999). There are multiple reports of various Bacillus spp. producing plant cell wall-degrading enzymes such as cellulases, xylanases and pectinases (Bano et al. 2013; Thite and Nerurkar 2015; Ghazala et al. 2015). This quality is normally not a primary criterion for the selection of probiotic strains for use as feed supplement. Consequently, there is a largely uncharted room for further improvement of such products by combining the traditional probiotic effects with more efficient utilisation of the feed. Using purified enzymes, we have previously demonstrated that prebiotic galacto-rhamnogalacturon fibers can be released from potato pulp by the action of pectin lyase and/or polygalacturonase (Thomassen et al. 2011; Strube et al. 2015a). Here, we used this as a model system and explored the possibility of identifying potentially probiotic strains of Bacillus that enable release of prebiotic fibers from potato pulp. The identification of such strains could have implications for the development of new health-beneficial feed supplements that could serve as an alternative to antibiotics to minimize GI disease in piglets.

We defined a suitable enzyme profile to consist of high amounts of secreted pectin lyase and/or polygalacturonase as well as no or low amounts of secreted galactanase and $\beta$ galactosidase as the latter would lead to degradation of the prebiotic fiber. For the initial screening we used a library of Bacillus strains previously characterised in vitro for probiotic potential in pigs (Larsen et al. 2014). This consisted of a diverse set of Bacillus species primarily isolated from feces, as this might improve the chance of isolating strains with the capability of spore outgrowth and survival in the GIT. This initial screen highlighted the potential of specifically $B$. amyloliquefaciens, B. subtilis, and B. mojavensis for which strains producing primarily fiber- 
releasing enzymes and minimal fiber degrading enzymes could be identified. We also observed that the majority of B. licheniformis and B. pumilis strains produced high levels of galactanase. While this characteristic is not relevant for this study, galactanase could potentially aid in the saccharification of lignocellulosic feed (de Lima et al. 2016) thus making these Bacillus species interesting for other applications including improvement of feed conversion.

Whether Bacillus spores are capable of readily germinating and growing in the GI tract has not been unequivocally proven, but it has been suggested that some of the probiotic effects of Bacillus species might be attributed to the spore itself (Leser et al. 2008; LaTorre et al. 2014). For the use of Bacillus as an in situ enzyme factory in the application in this study, vegetative cells are an absolute requirement. It was therefore of importance to make a preliminary assessment of the potential of the selected strains to proliferate, produce the desired enzymes, and release the fibers in a more relevant setting. In our simulated porcine GI tract model, we found that specifically strains of B. mojavensis were able to induce release of the desired fiber. Under the experimental conditions used, maximal fiber release was observed after 16-20 h. The transit time in the small intestine is normally estimated to be less than 7 hours (Strube et al. 2013). Conversely, Leser and co-workers found a substantial amount of vegetative Bacilli in the caecum of pigs $24 \mathrm{~h}$ after administration of two strains of B. subtilis and B. licheniformis (Leser et al. 2008). While it is not possible to directly extrapolate the kinetics from our simple in vitro system to the conditions in the GI tract in the piglet, our data suggest the possibility that the strains of B. mojavensis, when co-fed with potato pulp as a feed supplement, could release prebiotic fibers in the small intestine.

In a study analysing the antibiotic resistance, pathogen inhibition, sporulation efficiency, production of glycosyl hydrolases and biofilm formation of various Bacillus species, it was concluded that B. mojavensis as well as B. amyloliquefaciens, and B. subtilis have a better probiotic potential than B. licheniformis, B. megaterium, and B. pumilus (Larsen et al. 2014). Recently, it was also reported that B. mojavensis is an excellent producer of pectinase (Ghazala et al. 2015). B. mojavensis has thus far not been evaluated as a probiotic supplement in pigs, but it has been successfully applied in sea bass larvae where it improved growth performance and survival (Hamza et al. 2015).

This study has provided a first proof-of concept for selection of Bacillus strains with the potential to release prebiotic galacto-rhamnogalacturonan from potato pulp in the GI tract of piglets. While the data presented in this study are indicative that the application of Bacillus spores for targeted production of enzymes in vivo in the GI tract of piglets is possible, future experimental 
studies in piglets are needed to evaluate the retention time of the B. mojavensis strains in the piglet GI tract and the ability of the strains to release the necessary enzymes for release of prebiotics fibers in the porcine GI tract. Larger feeding trials will be needed to assess the potential health beneficial effects of these prebiotics fibers.

\section{Compliance with ethical standards}

\section{Funding}

This work was supported by a grant from the Green Development and Demonstration Programme (GUDP), Ministry of Environment and Food of Denmark (Grant no 34009-13-0700). The funders had no role in study design, data collection and interpretation, or the decision to submit the work for publication.

\section{Conflict of interest}

Authors MDC and BKKN are employed at Chr. Hansen A/S that sells Bacillus probiotics and OBS is employed at KMC amba, a producer of FiberBind. The authors declare that they have no conflict of interest.

\section{Ethical approval}

This article does not contain any studies with human participants or animals performed by any of the authors. 


\section{References}

Alexopoulos C, Georgoulakis IE, Tzivara A, Kyriakis CS, Govaris A, Kyriakis SC (2004) Field evaluation of the effect of a probiotic-containing Bacillus licheniformis and Bacillus subtilis spores on the health status, performance, and carcass quality of grower and finisher pigs. J Vet Med A Physiol Pathol Clin Med 51:306-312.

Altmeyer S, Kröger S, Vahjen W, Zentek J, Scharek-Tedin L (2014) Impact of a probiotic Bacillus cereus strain on the jejunal epithelial barrier and on the NKG2D expressing immune cells during the weaning phase of piglets. Vet Immunol Immunopathol 161:57-65.

Bano S, Qader SA, Aman A, Syed MN, Durrani K (2013) High production of cellulose degrading endo-1,4- $\beta$-D-glucanase using bagasse as a substrate from Bacillus subtilis KIBGE HAS. Carbohydr Polym 91:300-304.

Barbosa TM, Serra CR, La Ragione RM, Woodward MJ, Henriques AO (2005) Screening for Bacillus isolates in the broiler gastrointestinal tract. Appl Environ Microbiol 71:968-978.

Bhandari SK, Xu B, Nyachoti CM, Giesting DW, Krause DO (2008) Evaluation of alternatives to antibiotics using an Escherichia coli K88+ model of piglet diarrhea: effects on gut microbial ecology. J Anim Sci 86:836-847.

Cutting SM (2011) Bacillus probiotics. Food Microbiol 28:214-220.

de Lima EA, Machado CB, Zanphorlin LM, Ward RJ, Sato HH, Ruller R (2016) GH53 Endo-Beta1,4-Galactanase from a Newly Isolated Bacillus licheniformis CBMAI 1609 as an Enzymatic Cocktail Supplement for Biomass Saccharification. Appl Biochem Biotechnol 179:415-426

Fogel GB, Collins CR, Li J, Brunk CF (1999) Prokaryotic Genome Size and SSU rDNA Copy Number: Estimation of Microbial Relative Abundance from a Mixed Population. Microb Ecol 38:93-113. 
Ghazala I, Sayari N, Romdhane MB, Ellouz-Chaabouni S, Haddar A (2015) Assessment of pectinase production by Bacillus mojavensis I4 using an economical substrate and its potential application in oil sesame extraction. J Food Sci Technol 52:7710-7722.

Hamza A, Fdhila K, Zouiten D, Masmoudi AS (2016) Virgibacillus proomii and Bacillus mojavensis as probiotics in sea bass (Dicentrarchus labrax) larvae: effects on growth performance and digestive enzyme activities. Fish Physiol Biochem 42:495-507.

Huang JM, La Ragione RM, Nunez A, Cutting SM (2008) Immunostimulatory activity of Bacillus spores. FEMS Immunol Med Microbiol 53:195-203.

Jers C, Kobir A, Søndergaard EO, Jensen PR, Mijakovic I. (2011) Bacillus subtilis two-component system sensory kinase DegS is regulated by serine phosphorylation in its input domain. PLoS One 6:e14653.

Kang TJ, Basu S, Zhang L, Thomas KE, Vogel SN, Baillie L, Cross AS (2008) Bacillus anthracis spores and lethal toxin induce IL-1beta via functionally distinct signaling pathways. Eur J Immunol 38:1574-1584.

Kashyap DR, Vohra PK, Chopra S, Tewari R (2001) Applications of pectinases in the commercial sector: a review. Bioresour Technol 77:215-227.

Larsen N, Thorsen L, Kpikpi EN, Stuer-Lauridsen B, Cantor MD, Nielsen B, Brockmann E, Derkx PM, Jespersen L (2014) Characterization of Bacillus spp. strains for use as probiotic additives in pig feed. Appl Microbiol Biotechnol 98:1105-1118.

Latorre JD, Hernandez-Velasco X, Kallapura G, Menconi A, Pumford NR, Morgan MJ, Layton SL, Bielke LR, Hargis BM, Téllez G (2014) Evaluation of germination, distribution, and persistence of Bacillus subtilis spores through the gastrointestinal tract of chickens. Poult Sci 93:1793-1800.

Leser TD, Knarreborg A, Worm J (2008) Germination and outgrowth of Bacillus subtilis and Bacillus licheniformis spores in the gastrointestinal tract of pigs. J Appl Microbiol 104:1025-1033. 
Majeed M, Nagabhushanam K, Natarajan S, Sivakumar A, Eshuis-de Ruiter T, Booij-Veurink J, de Vries YP, Ali F (2016) Evaluation of genetic and phenotypic consistency of Bacillus coagulans MTCC 5856: a commercial probiotic strain. World J Microbiol Biotechnol 32:60.

Nakano MM, Dailly YP, Zuber P, Clark DP (1997) Characterization of anaerobic fermentative growth. J Bacteriol 179:6749-6755.

Ochiai A, Itoh T, Kawamata A, Hashimoto W, Murata K (2007) Plant cell wall degradation by saprophytic Bacillus subtilis strains: gene clusters responsible for rhamnogalacturonan depolymerization. Appl Environ Microbiol 73:3803-3813.

Okamoto K, Fujiya M, Nata T, Ueno N, Inaba Y, Ishikawa C, Ito T, Moriichi K, Tanabe H, Mizukami Y, Chang EB, Kohgo Y (2012) Competence and sporulation factor derived from Bacillus subtilis improves epithelial cell injury in intestinal inflammation via immunomodulation and cytoprotection. Int J Colorectal Dis 27:1039-1046.

Prieto ML, O'Sullivan L, Tan SP, McLoughlin P, Hughes H, Gutierrez M, Lane JA, Hickey RM, Lawlor PG, Gardiner GE (2014) In vitro assessment of marine Bacillus for use as livestock probiotics. Mar Drugs 12:2422-2445.

R Core Team (2012) R: A language and environment for statistical computing. R Foundation for Statistical Computing, Vienna, Austria. ISBN 3-900051-07-0, URL http://www.R-project.org/

Rasmussen LE, Meyer AS (2010) Size exclusion chromatography for the quantitative profiling of the enzyme-catalyzed hydrolysis of Xylo-oligosaccharides. J Agric Food Chem 58:762-769.

Schaeffer P, Millet J, Aubert JP (1965) Catabolic repression of bacterial sporulation. Proc Natl Acad Sci U S A 54:704-711. 
Scharek-Tedin L, Pieper R, Vahjen W, Tedin K, Neumann K, Zentek J (2013) Bacillus cereus var. Toyoi modulates the immune reaction and reduces the occurrence of diarrhea in piglets challenged with Salmonella Typhimurium DT104. J Anim Sci 91:5696-5704.

Strube ML, Meyer AS, Boye M (2013) Mini Review: Basic Physiology and Factors Influencing Exogenous Enzymes Activity in the Porcine Gastrointestinal Tract. Anim Nutr Feed Techn 13:441459.

Strube ML, Ravn HC, Ingerslev HC, Meyer AS, Boye M (2015a) In situ prebiotics for weaning piglets: in vitro production and fermentation of potato galacto-rhamnogalacturonan. Appl Environ Microbiol 81:1668-1678.

Strube ML, Jensen TK, Meyer AS, Boye M (2015b) In situ prebiotics: enzymatic release of galactorhamnogalacturonan from potato pulp in vivo in the gastrointestinal tract of the weaning piglet. AMB Express 5:66.

Tam NK, Uyen NQ, Hong HA, Duc le H, Hoa TT, Serra CR, Henriques AO, Cutting SM (2006) The intestinal life cycle of Bacillus subtilis and close relatives. J Bacteriol 188:2692-2700.

Thite VS, Nerurkar AS (2015) Xylanases of Bacillus spp. isolated from ruminant dung as potential accessory enzymes for agro-waste saccharification. Lett Appl Microbiol 60:456-466.

Thomassen LV, Vigsnæs LK, Licht TR, Mikkelsen JD, Meyer AS (2011) Maximal release of highly bifidogenic soluble dietary fibers from industrial potato pulp by minimal enzymatic treatment. Appl Microbiol Biotechnol 90:873-884.

Torres S, Sayago JE, Ordoñez RM, Isla MI (2011) A colorimetric method to quantify endopolygalacturonase activity. Enzyme Microb Technol 48:123-128.

Trejo M, Douarche C, Bailleux V, Poulard C, Mariot S, Regeard C, Raspaud E (2013) Elasticity and wrinkled morphology of Bacillus subtilis pellicles. Proc Natl Acad Sci U S A 110:2011-2016. 
Tsukahara T, Tsuruta T, Nakanishi N, Hikita C, Mochizuki M, Nakayama K (2013) The preventive effect of Bacillus subtilus strain DB9011 against experimental infection with enterotoxcemic Escherichia coli in weaning piglets. Anim Sci J 84:316-321.

van den Broek LAM, den Aantrekker ED, Voragen AGJ, Beldman G, Vincken JP (1997) Pectin lyase is a key enzyme in the maceration of potato tuber. J Sci Food Agric 75:167-172.

Yadav S, Yadav PK, Ydav D, Ydav KDS (2009) Pectin lyase: a review. Process Biochem 44:1-10. 


\section{Figure legends}

Fig. 1. Enzymatic release of rhamnogalacturonan from potato pulp using secreted enzymes from Bacillus strains. Panel a shows for all tested strains, the release of fibers with a molecular weight higher than $110 \mathrm{kDa}$ at time point 6 h. N.C. is a negative control. Different roman letters show significantly different means as determined by Tukey's HSD test. Panels b and c shows the amounts of precipitated, water-soluble fibers at different time points (left) and the size distribution of the fibers as analysed by HPSEC (right). Retention times of molecular standards in HPSEC are indicated by symbols: $800 \mathrm{kDa}$ (square), $400 \mathrm{kDa}$ (triangle), $110 \mathrm{kDa}$ (diamond), $12 \mathrm{kDa}$ (circle), and $1.3 \mathrm{kDa}$ (cross). Panel b shows the data obtained with extract from B. subtilis 5036 that led to the highest release of fiber. Panel c shows the data for B. subtilis 9927 that did not release fibers.

Fig. 2. Enzymatic release of rhamnogalacturonan from potato pulp using spores from Bacillus strains in vitro under simulated GI conditions. The experimental setup included $1 \mathrm{~h}$ under gastric conditions followed by incubation under simulated small intestinal conditions for the time periods indicated in the figure. Panel a shows for all tested strains, the release of fibers with a molecular weight higher than $110 \mathrm{kDa}$ at time point $20 \mathrm{~h}$. N.C. is a negative control. Different roman letters show significantly different means as determined by Tukey's HSD test. Panels b and c shows the amounts of precipitated, water-soluble fibers at different time points (left) and the size distribution of the fibers as analysed by HPSEC (right) for the best performing strains B. mojavensis strains 10894 and 15079, respectively. Retention times of molecular standards in HPSEC are indicated by symbols: $800 \mathrm{kDa}$ (square), $400 \mathrm{kDa}$ (triangle), $110 \mathrm{kDa}$ (diamond), $12 \mathrm{kDa}$ (circle), and $1.3 \mathrm{kDa}$ (cross). 


\section{Tables}

Table 1. Summary of screening results for strains selected for further analysis.

\begin{tabular}{|c|c|c|c|c|c|c|c|c|c|c|}
\hline \multirow[t]{2}{*}{ Strain ID } & \multirow[t]{2}{*}{ Source } & \multirow{2}{*}{$\begin{array}{l}\text { Growth } \\
\text { LB/MM }\end{array}$} & \multicolumn{2}{|c|}{$\begin{array}{c}\text { Pectin lyase } \\
{\left[10 * \mathrm{Abs}_{235} / \mathrm{h}\right]}\end{array}$} & \multicolumn{2}{|c|}{$\begin{array}{l}\text { Polygalacturonase } \\
{\left[100 * \mathrm{Abs}_{535} / \mathrm{h}\right]}\end{array}$} & \multicolumn{2}{|c|}{$\begin{array}{c}\text { Galactanase } \\
{\left[10 * \mathrm{Abs}_{590} / \mathrm{h}\right]}\end{array}$} & \multicolumn{2}{|c|}{$\begin{array}{c}\beta \text {-Galactosidase } \\
{\left[10 * \operatorname{Abs}_{590} / \mathrm{h}\right]}\end{array}$} \\
\hline & & & LB & MM & $\mathrm{LB}$ & MM & LB & MM & LB & $\mathrm{MM}$ \\
\hline \multicolumn{11}{|c|}{ Bacillus amyloliquefaciens } \\
\hline 4091 & Soil & $* * / *$ & $0.0 \pm 0.2$ & $1.0 \pm 0.2$ & $3.9 \pm 0.9$ & $3.0 \pm 0.9$ & $0.03 \pm 0.00$ & $0.02 \pm 0.00$ & $\mathrm{BDL}^{\mathrm{B}}$ & $\mathrm{BDL}^{\mathrm{B}}$ \\
\hline 14623 & Feces & $* * * / *$ & $0.3 \pm 0.4$ & $1.4 \pm 0.2$ & $3.6 \pm 0.3$ & $3.5 \pm 0.1$ & $0.08 \pm 0.00$ & $0.03 \pm 0.00$ & $\mathrm{BDL}^{\mathrm{B}}$ & $0.00 \pm 0.01$ \\
\hline 15078 & Feces & $* * / * *$ & $2.1 \pm 0.5$ & $2.2 \pm 0.4$ & $1.4 \pm 0.6$ & $0.5 \pm 0.2$ & $0.03 \pm 0.01$ & $0.02 \pm 0.01$ & $\mathrm{BDL}^{\mathrm{B}}$ & $0.01 \pm 0.01$ \\
\hline 15084 & Feces & $* * * / * *$ & $0.6 \pm 0.2$ & $1.2 \pm 0.2$ & $4.5 \pm 0.2$ & $3.2 \pm 1.0$ & $0.18 \pm 0.01$ & $0.14 \pm 0.00$ & $\mathrm{BDL}^{\mathrm{B}}$ & $0.00 \pm 0.00$ \\
\hline 15109 & Feces & $* * / * *$ & $0.3 \pm 0.3$ & $1.0 \pm 0.2$ & $4.4 \pm 0.7$ & $2.8 \pm 1.0$ & $0.07 \pm 0.04$ & $0.02 \pm 0.00$ & $\mathrm{BDL}^{\mathrm{B}}$ & $0.00 \pm 0.01$ \\
\hline 15111 & Feces & $* * / *$ & $0.7 \pm 0.4$ & $1.8 \pm 0.2$ & $2.6 \pm 1.5$ & $0.9 \pm 0.3$ & $0.01 \pm 0.00$ & $0.01 \pm 0.00$ & $\mathrm{BDL}^{\mathrm{B}}$ & $0.00 \pm 0.00$ \\
\hline 15149 & Feces & $* * / *$ & $0.8 \pm 0.5$ & $1.2 \pm 0.2$ & $3.6 \pm 0.4$ & $0.8 \pm 0.1$ & $0.03 \pm 0.02$ & $0.02 \pm 0.00$ & $\mathrm{BDL}^{\mathrm{B}}$ & $0.01 \pm 0.02$ \\
\hline 15155 & Feces & $* * / * *$ & $1.2 \pm 0.5$ & $0.9 \pm 0.2$ & $3.3 \pm 1.3$ & $0.4 \pm 0.1$ & $0.04 \pm 0.00$ & $0.02 \pm 0.00$ & $\mathrm{BDL}^{\mathrm{B}}$ & $0.01 \pm 0.01$ \\
\hline 15157 & Feces & $* * / * *$ & $0.7 \pm 0.3$ & $1.3 \pm 0.2$ & $2.9 \pm 1.6$ & $0.5 \pm 0.3$ & $0.06 \pm 0.02$ & $0.02 \pm 0.00$ & $\mathrm{BDL}^{\mathrm{B}}$ & $0.00 \pm 0.01$ \\
\hline 15158 & Feces & $* * / *$ & $0.0 \pm 0.2$ & $1.0 \pm 0.2$ & $3.6 \pm 1.8$ & $0.8 \pm 0.2$ & $0.04 \pm 0.02$ & $0.01 \pm 0.00$ & $\mathrm{BDL}^{\mathrm{B}}$ & $0.00 \pm 0.01$ \\
\hline 15161 & Feces & $* * / * *$ & $0.9 \pm 0.4$ & $1.2 \pm 0.2$ & $3.5 \pm 0.5$ & $1.2 \pm 0.3$ & $0.05 \pm 0.01$ & $0.01 \pm 0.00$ & $\mathrm{BDL}^{\mathrm{B}}$ & $0.02 \pm 0.01$ \\
\hline 15169 & Feces & $* * * / * *$ & $1.0 \pm 0.3$ & $1.4 \pm 0.2$ & $2.8 \pm 0.7$ & $0.7 \pm 0.1$ & $0.06 \pm 0.05$ & $0.02 \pm 0.00$ & $\mathrm{BDL}^{\mathrm{B}}$ & $0.02 \pm 0.00$ \\
\hline \multicolumn{11}{|c|}{ Bacillus mojavensis } \\
\hline 10894 & Feces & $* * / * *$ & $3.1 \pm 0.2$ & $0.8 \pm 0.2$ & $5.8 \pm 0.1$ & $5.0 \pm 0.6$ & $0.28 \pm 0.02$ & $0.07 \pm 0.01$ & $0.18 \pm 0.05$ & $0.12 \pm 0.01$ \\
\hline 15079 & Feces & $* * * / * *$ & $2.0 \pm 0.3$ & $0.6 \pm 0.2$ & $6.0 \pm 0.8$ & $3.4 \pm 0.6$ & $0.43 \pm 0.07$ & $0.14 \pm 0.01$ & $0.12 \pm 0.03$ & $0.05 \pm 0.00$ \\
\hline \multicolumn{11}{|c|}{ Bacillus subtilis } \\
\hline 3810 & $\begin{array}{l}\text { Soy } \\
\text { bean }\end{array}$ & $* * / * *$ & $4.1 \pm 0.6$ & $2.2 \pm 0.2$ & $4.5 \pm 0.4$ & $3.6 \pm 1.0$ & $0.70 \pm 0.05$ & $0.17 \pm 0.01$ & $0.38 \pm 0.09$ & $0.52 \pm 0.03$ \\
\hline 4208 & $\mathrm{CC}^{\mathrm{C}}$ & $* * / * *$ & $1.7 \pm 0.2$ & $0.5 \pm 0.2$ & $7.1 \pm 0.2$ & $5.3 \pm 0.6$ & $0.00 \pm 0.00$ & $0.03 \pm 0.00$ & $\mathrm{BDL}^{\mathrm{B}}$ & $0.02 \pm 0.01$ \\
\hline 5036 & $\mathrm{CC}^{\mathrm{C}}$ & $* / * *$ & $1.2 \pm 0.2$ & $1.1 \pm 0.2$ & $3.5 \pm 1.2$ & $1.7 \pm 0.4$ & $0.00 \pm 0.01$ & $0.03 \pm 0.00$ & $\mathrm{BDL}^{\mathrm{B}}$ & $0.05 \pm 0.01$ \\
\hline 10891 & Feces & $* * / * *$ & $2.9 \pm 0.3$ & $1.2 \pm 0.2$ & $6.1 \pm 0.3$ & $5.7 \pm 0.5$ & $0.11 \pm 0.02$ & $0.04 \pm 0.01$ & $0.24 \pm 0.06$ & $0.41 \pm 0.04$ \\
\hline 15130 & Feces & $* * / * *$ & $6.0 \pm 0.2$ & $3.1 \pm 0.2$ & $6.4 \pm 0.7$ & $5.5 \pm 0.5$ & $0.75 \pm 0.02$ & $0.57 \pm 0.05$ & $0.17 \pm 0.02$ & $0.30 \pm 0.02$ \\
\hline 15179 & Feces & $* * * / *$ & $2.9 \pm 0.3$ & $1.6 \pm 0.2$ & $4.0 \pm 0.0$ & $5.7 \pm 0.5$ & $0.68 \pm 0.09$ & $0.34 \pm 0.02$ & $0.37 \pm 0.12$ & $0.29 \pm 0.07$ \\
\hline $9927^{\mathrm{A}}$ & Feces & $* / *$ & $\mathrm{BDL}^{\mathrm{B}}$ & $2.0 \pm 0.3$ & $\mathrm{BDL}^{\mathrm{B}}$ & $0.8 \pm 0.1$ & $0.52 \pm 0.04$ & $0.30 \pm 0.09$ & $0.03 \pm 0.00$ & $0.55 \pm 0.05$ \\
\hline
\end{tabular}

${ }^{\mathrm{A}}$ Strain 9927 was chosen to function as a negative control.

${ }^{\mathrm{B}}$ BDL: Below detection limit

${ }^{\mathrm{C}} \mathrm{CC}$ : Culture collection

Table 2. Composition of fibers released under in vitro simulated GI conditions by B. mojavensis strains and enzymatically using pectin lyase and polygalacturonase.

\begin{tabular}{lccccccc}
\hline Fiber type & Rha & Ara & Gal & Glc & Xyl & GalA & NA $^{\mathrm{A}}$ \\
\hline B. mojavensis 15079 & $1.3 \pm 0.0$ & $4.4 \pm 0.1$ & $27.0 \pm 0.9$ & $3.2 \pm 0.1$ & $2.9 \pm 0.1$ & $19.7 \pm 0.9$ & 41.45 \\
B. mojavensis 10894 & $1.5 \pm 0.2$ & $3.8 \pm 0.2$ & $29.3 \pm 1.3$ & $2.9 \pm 0.1$ & $2.3 \pm 0.2$ & $18.9 \pm 1.7$ & 41.26 \\
Enzyme extraction $^{\mathrm{B}}$ & $3.4 \pm 0.4$ & $6.5 \pm 0.8$ & $36.3 \pm 3.6$ & $2.4 \pm 0.4$ & $0.0 \pm 0.0$ & $20.3 \pm 5.0$ & 31.10 \\
\hline
\end{tabular}

${ }^{\mathrm{A}} \mathrm{NA}$, nonaccountable (including protein content)

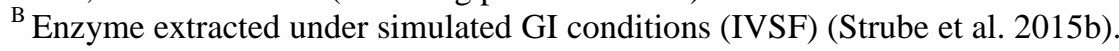


Figure 1
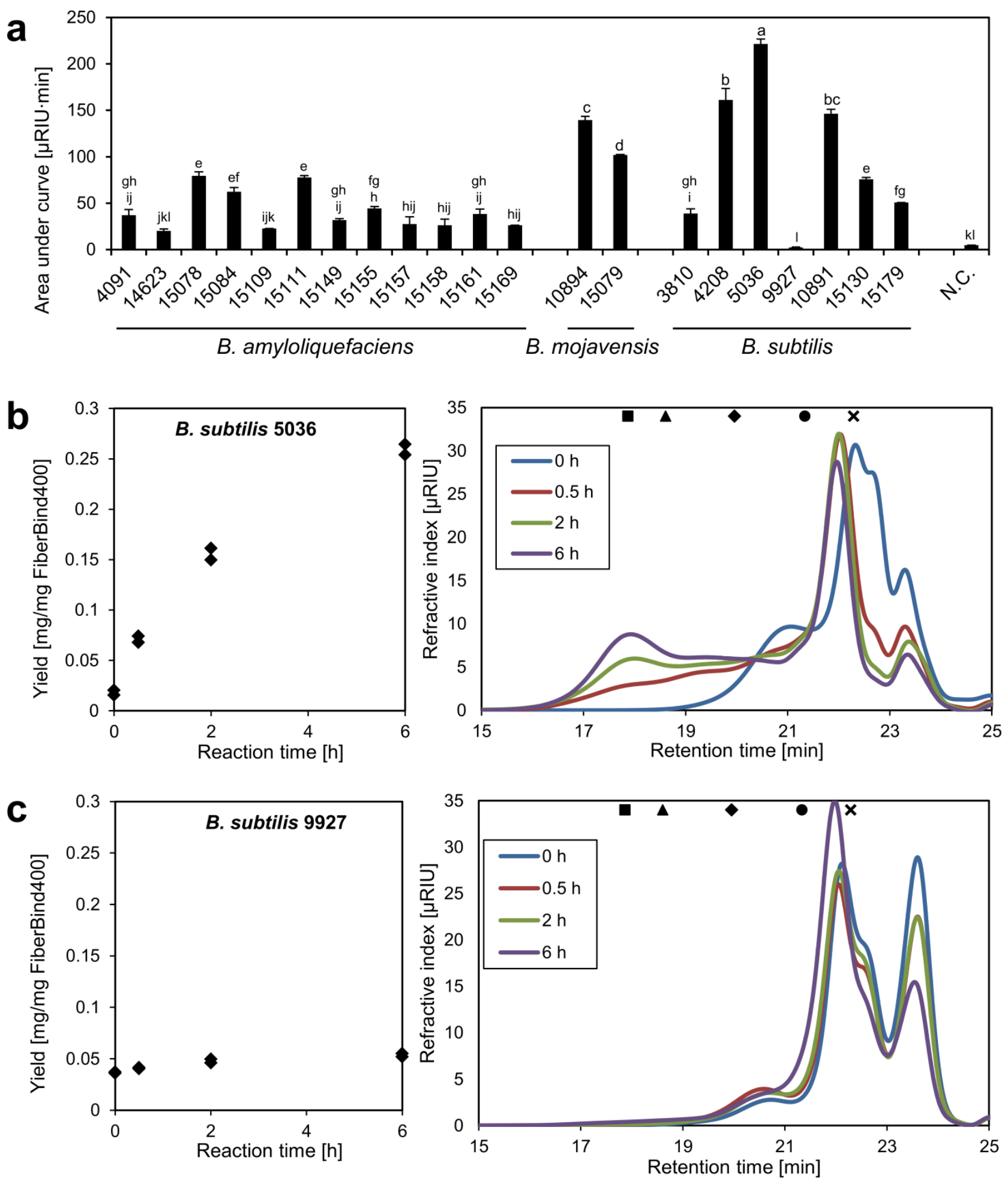
Figure 2
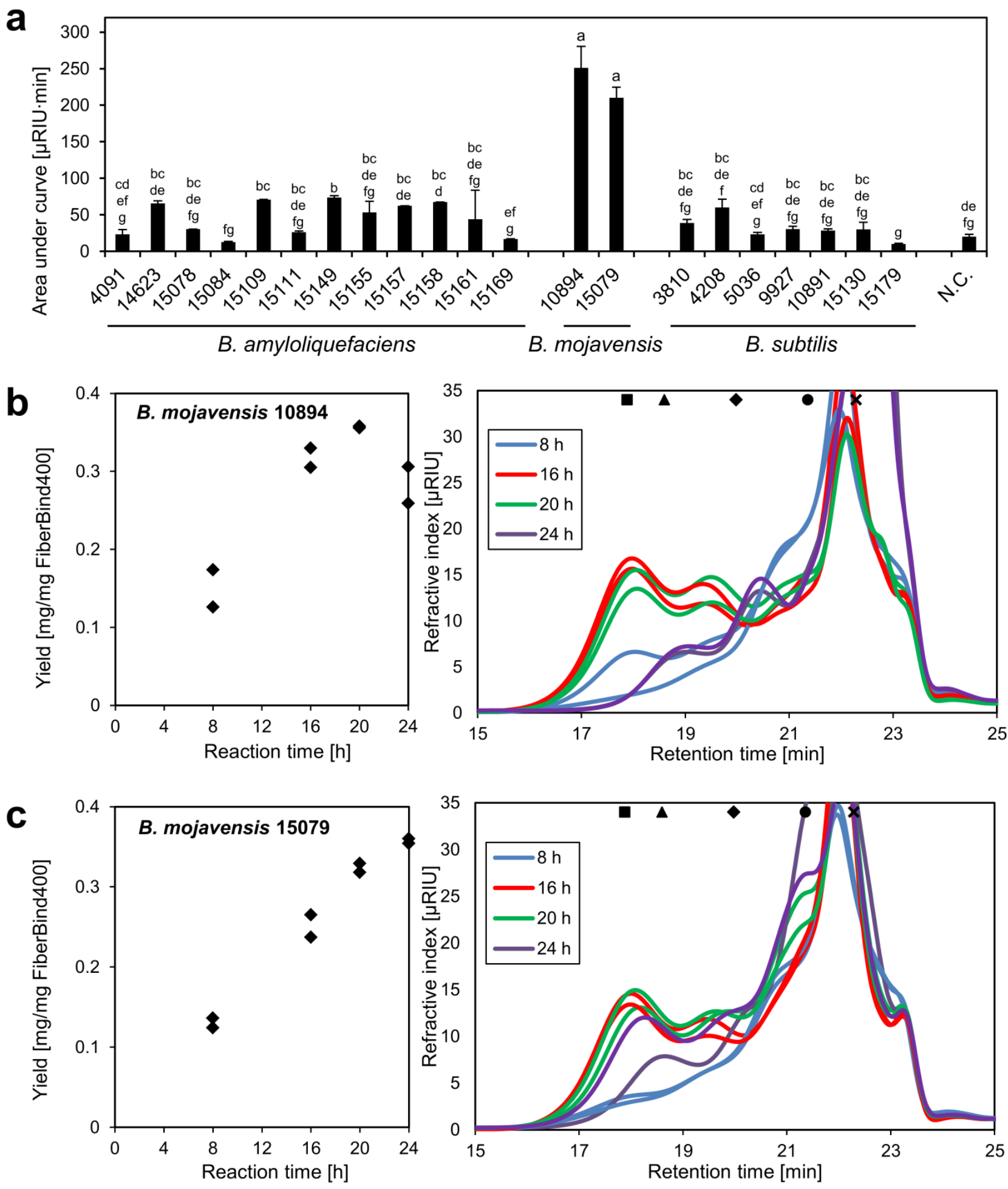